\title{
Sistem Konsultasi dan Bimbingan Online Berbasis Web Menggunakan Webrtc (Studi Kasus : Fakultas Teknik Universitas Suryakancana)
}

\author{
Tarmin Abdulghani ${ }^{1}$, Muhammad Maulana Hamzah Gozali ${ }^{2}$ \\ Program Studi Teknik Informatika \\ Universitas Suryakancana \\ tamrin@unsur.ac.id, hamzahgozali13@gmail.com
}

\begin{abstract}
Abstrak
Dengan banyaknya jumlah mahasiswa, yang harus dibimbing banyak dan tugas lain seperti mengajar, membimbing Kerja Praktek Lapangan dan Tugas Proyek, jabatan structural mengakibatkan dosen pembimbing Tugas Akhir kurang optimal dalam memberikan bimbingan, terlebih lagi bagi mahasiswa yang sering menunda-nunda pengerjaan Tugas Akhir atau sulitnya mahasiswa jika ingin menemui dosen untuk bimbingan. Dampak bagi prodi dari hal ini adalah menurunnya produktifitas prodi. Dalam hal ini adanya suatu inovasi ataupun terobosan baru, yaitu sistem konsultasi dan bimbingan online sebagai solusi dalam hal masalah ini untuk berkonsultasi dan bimbingan dengan mahasiswa dan dosen baik kegiatan akademik maupun non-akademik.
\end{abstract}

Kata kunci : Konsultasi, Tugas Akhir, WebAbstrak

\section{Pendahuluan}

Fakultas Teknik merupakan salah satu fakultas yang ada di lingkungan Universitas Suryakancana Cianjur, terletak di Jalan Pasir Gede Raya Cianjur, yang didirikan berdasarkan Surat Keputusan Mendiknas RI No. 100/D/O/2001 tanggal 2 Agustus 2001 di Cianjur dan merupakan gabungan dari dua fakultas yaitu Program studi Teknik Sipil dan Perencanaan dan Program Studi Teknologi Industri, sebagaimana dituangkan dalam Surat Keputusan Rektor No. 09/SK/SN/UNSUR/IX/2003 tanggal 27 Agustus 2003.

Fakultas Teknik Universitas Suryakancana Cianjur saat ini memiliki 3 (tiga) Jurusan yaitu Program Studi Teknik Informatika, Program Studi Teknik Industri, dan Program Studi Teknik Sipil. Kehadiran Jurusan-Jurusan yang ada di Fakultas Teknik Universitas Suryakancana Cianjur, diharapkan dapat mempersiapkan kebutuhan tenaga-tenaga profesional di Kabupaten Cianjur dalam pengembangan dan pembangunan bidang teknologi di tingkat regional maupun nasional. Berkaitan dengan adanya kebijakan otonomi daerah yang secara tidak langsung menuntut para lulusan Fakultas Teknik untuk menguasai kondisi daerah dan mampu meningkatkan efisiensi pembangunan serta siap melakukan percepatan pembangunan secara terintegrasi dan berkelanjutan. Dengan demikian akan memberikan peluang kerja bagi lulusan Fakultas Teknik dalam mengembangakan dan meningkatkan pembangunan Jawa Barat khususnya Kabupaten Cianjur.

Pada pelaksanaan penelitian Tugas Akhir (TA), mahasiswa diwajibkan melakukan konsultasi dengan Koordinator Tugas Akhir untuk pengajuan judul penelitian Tugas Akhir setelah pengajuan judul tugas akhir telah disetujui mahasiswa dapat melakukan bimbingan kepada dosen pembimbing untuk dapat melanjutkan penelitian tugas akhir. Penelitian Tugas
Akhir ini yang bertujuan untuk mendapatkan gelar kersarjanaan di suatu perguruan tinggi yaitu di Universitas Suryakancana.

Dengan banyaknya jumlah mahasiswa yang harus dibimbing banyak dan tugas lain seperti mengajar, membimbing Kerja Praktek Lapangan dan Tugas Proyek, jabatan structural mengakibatkan dosen pembimbing Tugas Akhir kurang optimal dalam memberikan bimbingan, terlebih lagi bagi mahasiswa yang sering menunda-nunda pengerjaan Tugas Akhir atau sulitnya mahasiswa jika ingin menemui dosen untuk bimbingan. Dampak bagi prodi dari hal ini adalah menurunnya produktifitas prodi.

Pada saat ini pihak prodi sudah menyediakan sebuah sistem e-library edisi tugas akhir yang dapat membantu dan mempermudah untuk mengerjakan penelitian tugas akhir dan pihak dosen pun terbantu dengan adanya sistem tersebut, namun masih adanya kekurangan dalam hal konsultasi dan bimbingan dengan pihak dosen pembimbing maupun pihak mahasiswa, yang terkadang mahasiswa yang sering menunda nunda pengerjaan tugas akhir dan pihak dosen pembimbingpun khawatir kepada mahasiswa anak didiknya.

Dalam hal ini sistem konsultasi dan bimbingan online sebagai solusi dalam hal masalah ini untuk berkonsultasi dan bimbingan dengan mahasiswa dan dosen baik kegiatan akademik maupun non-akademik. Sistem konsultasi dan bimbingan online ini memiliki beberapa fitur seperti live video stream dan live chatting, agar mahasiswa dan dosen dapat berkomunikasi secara langsung dan juga dapat mengurangi waktu dalam jarak dari rumah ke kampus untuk bertemu dosen maupun mahasiswa.

Dalam penelitian ini akan menganalisis dan membuat aplikasi sistem konsultasi dan bimbingan online berbasis web di Fakultas Teknik Universitas Suryakanacana agar dapat membantu mengurangi ataupun meminimalisir permasalahan yang sering terjadi 
dalam hal bimbingan dan konsultasi penelitian tugas akhir sebagai suatu terobosan atau inovasi dalam permasalahan bimbingan dan konsultasi mahasiswa dan dosen untuk penelitian Tugas Akhir.

Maksud penelitian ini adalah membuat dan merancang modeling sistem konsultasi dan bimbingan online berbasis website yang diharapkan mampu digunakan oleh Mahasiswa dan Dosen.

Tujuan dari penelitian ini adalah sebagai berikut :

a. Membantu Mahasiswa dengan Dosen dalam hal berkomunikasi.

b. Mempermudah dan mengurangi masalah dalam hal konsultasi dan bimbingan Mahasiswa dengan Dosen. Mengembangkan aplikasi bimbingan online menggunakan webrtc.

\section{Landasan Teori}

\subsection{Definisi Sistem}

Sistem berasal dari bahasa Latin (systèma) dan bahasa Yunani (sustēma) adalah suatu kesatuan yang terdiri komponen atau elemen yang dihubungkan bersama untuk memudahkan aliran informasi, materi atau energi untuk mencapai suatu tujuan. Istilah ini sering dipergunakan untuk menggambarkan suatu set entitas yang berinteraksi, di mana suatu model matematika seringkali bisa dibuat.

Sistem juga merupakan kesatuan bagian-bagian yang saling berhubungan yang berada dalam suatu wilayah serta memiliki item-item penggerak, contoh umum misalnya seperti negara. Negara merupakan suatu kumpulan dari beberapa elemen kesatuan lain seperti provinsi yang saling berhubungan sehingga membentuk suatu negara di mana yang berperan sebagai penggeraknya yaitu rakyat yang berada dinegara tersebut. Kata "sistem" banyak sekali digunakan dalam percakapan sehari-hari, dalam forum diskusi maupun dokumen ilmiah. Kata ini digunakan untuk banyak hal, dan pada banyak bidang pula, sehingga maknanya menjadi beragam. Dalam pengertian yang paling umum, sebuah sistem adalah sekumpulan benda yang memiliki hubungan di antara mereka.(Eriyanto 2012)

\subsection{Definisi Konsultasi dan Konsultasi}

Pengertian konsultasi menurut Dougherty dalam Sukendro (2007:51) adalah suatu bentuk hubungan tolong menolong yang dilakukan oleh seorang professional yang disebut konsultan. Selain itu konsultasi diartikan sebagai pertimbangan orang terhadap suatu masalah. (Dedy Bagus Rusdianto, Titik Lusiani n.d.)

Bimbingan dan Konseling adalah upaya sistematis, objektif, logis, dan berkelanjutan serta terprogram yang dilakukan oleh konselor atau guru Bimbingan dan Konseling untuk memfasilitasi perkembangan peserta didik/Konseli untuk mencapai kemandirian dalam kehidupannya. (Ministry of Education and Culture 2014)

\subsection{Definisi Online}

Online adalah terhubung, terkoneksi, aktif dan siap untuk operasi, dapat berkomunikasi dengan atau dikontrol oleh komputer.

Online dapat diartikan sebagai suatu keadaan yang sedang menggunakan jaringan, terhubung dalam jaringan, satu perangkat dengan perangkat lainnya yang terhubung sehingga bisa saling berkomunikasi.(Sisca rizki aprilia 2013)

\subsection{Definisi Website}

Website disebut sebagai fasilitas internet, dimana mengkaitkan dokumen dilingkup local maupun jarak jauh. Dokumen tersebut dengan web page dan link website memungkinkan pengguna bisa berpindah page (hyper text), baik diantara page yang disimpan server yang sama maupun server diseluruh dunia. Browser yang digunakan untuk mengakses dan membaca pages diantaranya netscape navigator, google chrome, internet explorer, mozila firefox, dan lain sebagainya. (Lukmanul Hakim 2004)

\subsection{Definisi WebRTC}

WebRTC (Web Real Time Communications) adalah teknologi web yang memungkinkan terjadinya komunikasi antar browser secara real time dengan melalui berbagai media, seperti media suara, teks dan video. WebRTC juga dapat bekerja pada banyak web browser, antar platform atau sistem operasi, baik komputer maupun mobile device. Hadirnya teknologi ini juga memberikan banyak keuntungan untuk user.

WebRTC adalah teknologi yang sangat baru dan masih terus dikembangkan. Jadi, sekarang ini masih ada platform dan web browser yang tidak mendukung WebRTC dan ada yang hanya mendukung sebagian dari WebRTC. (Sitepu, Muchma, and Angela 2006)

WebRTC adalah (Real time communication) adalah teknologi web yang memungkinkan terjadinya komunikasi antara browser secara real time dengan melalui berbagai media, seperti media suara, teks dan video. WebRTC menghadirkan fitur pada peramban web untuk berbagi data dan melakukan telekonferensi secara peer to peer, tanpa perlu memasang plugins atau aplikasi pihak ketiga. Komponen WebRTC dapat diakses melalui JavaScript API, di antaranya: Network Stream API, yang mempresentasikan audio atau video dalam bentuk data stream, PeerConnection API, yang memungkinkan dua atau lebih pengguna untuk berkomunikasi langsung memalui peramban web, dan DataChannel API, yang memungkinkan bentuk komunikasi lainnya secara realtime untuk gaming, text chat, file transfer, dan lainya. 


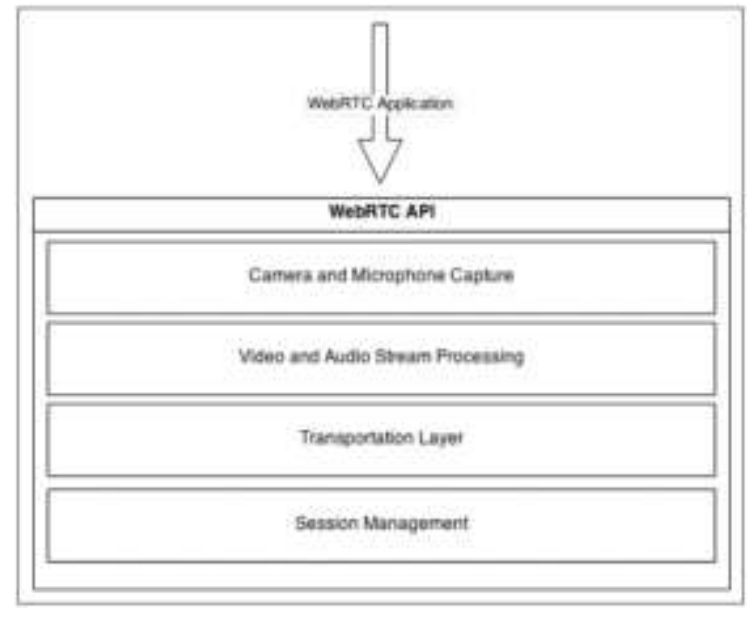

Gambar 1 Arsitektur WebRTC

\section{Metode Penelitian}

Metode penelitian yang digunakan yaitu waterfall. Menurut Pressman (2015), nama lain dari Model waterfall adalah model air terjun kadang disebut klasik life cycle, menunjukkan sebuah sistematika yang berurutan untuk pengembangan perangkat lunak yang diawali dengan spesifikasi persyaratan yang dibutuhkan oleh customer dan kemajuan melalui perencanaan, pemodelan, konstruksi, dan penyebaran yang berpuncak pada dukungan yang berkelanjutan dari perangkat lunak yang telah selesai. Adapun alat bantu berupa UML (Unified Modeling Language).(Roger S. Pressman 2012)

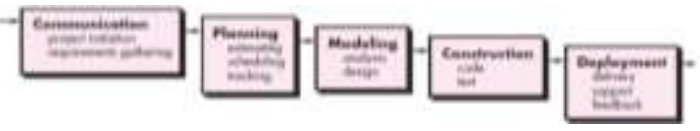

Gambar 2 Metodologi Waterfall

\section{Perangkat Pembangunan Website}

Untuk membangun sebuah website diperlukan berbagai perangkat seperti Bahasa pemograman, database, dan juga web browser. Berikut ini adalah Bahasa pemograman, database dan juga web browser yang digunakan dalam membangun website:

a. HTML

HTML adalah singkatan dari HyperText Markup Language yaitu bahasa pemrograman standar yang digunakan untuk membuat sebuah halaman web, yang kemudian dapat diakses untuk menampilkan berbagai informasi di dalam sebuah penjelajah web internet (Browser).

b. CSS

Cascading Style Sheet (CSS) merupakan aturan untuk mengendalikan beberapa komponen dalam sebuah web sehingga akan lebih terstruktur dan seragam. Cascading Style Sheet (CSS) bukan termasuk dalam bahasa pemrograman, namun sama halnya seperty style dalam aplikasi pengolahan kata Microsoft Word yang dapat mengatur beberapa style seperti heading, subbab, bodytext, footer, images, dan style lainnya.

\section{c. PHP}

Pada awalnya PHP merupakan singkatan dari Personal Home Page, yang gunanya untuk memonitor pengunjung suatu web. PHP mula-mula dikembangkan oleh Rasmus Lerdofr. Istilah PHP kemudian mengacu pada Hypertext Preprcessor. PHP kemudian lebih dikembangkan untuk membangun aplikasi web yang mendukung database. Biasanya dipasangkan dengan Mysql. PHP ini merupakan bahasa pemrograman yang dapat digunakan untuk membuat skrip yang lebih interaktif. Skrip ini akan diolah dalam web server yang hasilnya dapat dilihat dalam bentuk HTML.

\section{d. MySQL}

MySQL adalah sebuah server database open source yang terkenal yang digunakan berbagai aplikasi terutama untuk server atau membuat web. Mysql berfungsi sebagai SQL (Structured Query Language) yang dimiliki sendiri dan sudah diperluas oleh Mysql umumnya digunakan bersamaan dengan PHP untuk membuat aplikasi server yang dinamis. (Abdulloh 2015)

\section{e. NodeJS}

Javascript merupakan Bahasa pemrograman yang lengkap hanya saja selama ini di pakai sebagai Bahasa untuk pengembangan aplikasi web yang berjalan pada sisi client atau browser saja. Tetapi sejak ditemukannya Node.js oleh Ryan Dhal pada tahun 2009, Javascript bisa digunakan sebagai bahasa pemrograman di sisi server sekelas dengan PHP, ASP, C\#, Ruby dll dengan kata lain Node.js menyediakan platform untuk membuat aplikasi Javascript dapat dijalankan di sisi server. Untuk mengeksekusi Javascript sebagai bahasa server diperlukan engine yang cepat dan mempunyai performansi yang bagus. Engine Javascript dari Google bernama V8 yang dipakai oleh Node.js yang merupakan engine yang sama yang dipakai di browser Google Chrome.(Pr 2012)

f. Web Browser

Web Browser disebut juga sebagai perambah, adalah perangkat lunak yang berfungsi menampilkan dan melakukan interaksi dengan dokumen-dokumen yang disediakan oleh server web.Google Chrome adalah sebuah aplikasi peramban yang digunakan untuk menjelajah dunia maya seperti halnya Firefox, Opera ataupun Microsoft Edge. Jika Firefox dikembangkan oleh Mozilla, Google Chrome dibuat dan dirancang oleh Google, perusahaan internet terbesar di dunia yang juga empunya android. Web Browser digunakan untuk menampilkan hasil website yang telah dibuat. Web browser yang paling sering digunakan diantaranya adalah, Mozilla Firefox, Google Chrome dan Safari.(Abdulloh 2015)

\section{Analisis Sistem}

\subsection{Analisis webrtc}

Analisis webrtc adalah suatu analisis yang menjelaskan tentang webrtc, yang berisikan tenang arsitektur, topologi webrtc.

a. Arsitektur webrtc

Arsitektur yang umum digunakan adalah dimana 
kedua pengguna menjalankan aplikasi WebRTC yang sama, diunduh dari halaman web yang sama, sehingga menghasilkan hubungan seperti bentuk segi empat. Penyusunan ini dinamakan segiempat karena bentuk dari pengiriman sinyal dan alur media/data antara ketiga element ini.

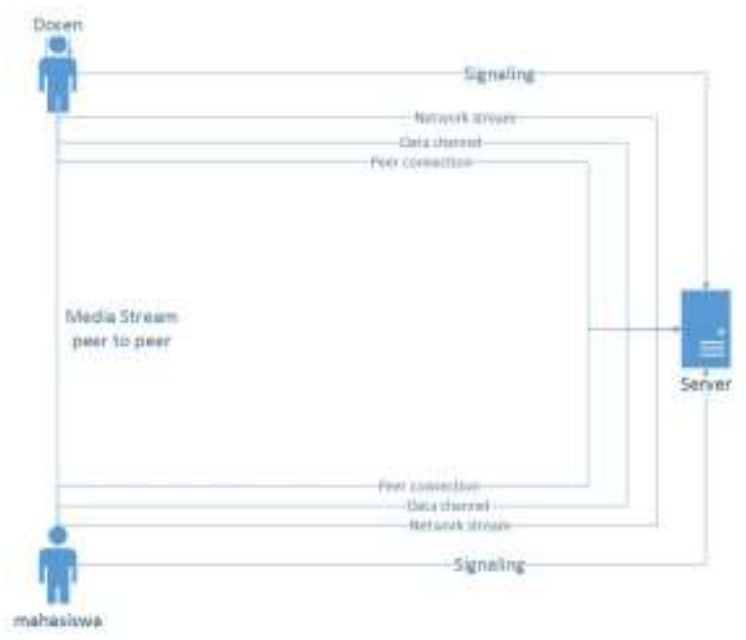

Gambar 3 Arsitektur WebRTC

Arsitektur webrtc untuk sistem konsultasi dan bimbingan online berbasis web menggunakan webrtc studi kasus Fakultas Teknik Universitas Suryakancana. Rancangan ini menunjukkan apa saja yang dapat dilakukan oleh sistem tersebut dan seperti apa interaksi antar pengguna dengan server dalam melayani sistem konsultasi dan bimbingan online.

Pada sistem konsultasi dan bimbingan online ini terdapat 2 pengguna yang dapat berhubungan dengan sistem, yakni dosen dan mahasiswa. Pada sistem ini dosen dan mahasiswa membuat koneksi dengan server untuk mengubungkan dan menjalankan aplikasi webrtc tersebut. Dan beberapa komponen yang dapat dilakukan oleh pengguna yaitu ada Network stream, Data channel, dan peer connection. Network stream adalah pengguna dapat melakukan data stream yang sudah dipresentasi dari audio dan video secara realtime, Data channel adalah pengguna dapat melakukan chatting dan file transfer dengan sesama pengguna, dan Peer connection adalah pengguna dapat melakukan komunikasi secara langsung melalui media web.

b. Topologi webrtc

Topologi yang digunakan untuk sistem ini adalah topologi star yaitu sistem ini maksimal hanya bisa digunakan oleh 5 pengguna.

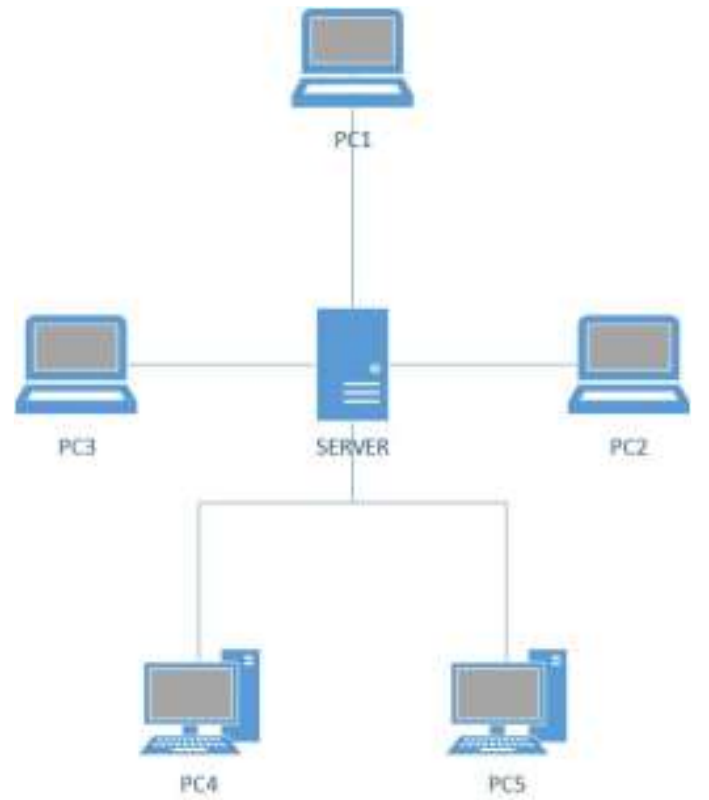

Gambar 4 Topologi WebRTC

Server web berada pada satu lingkungan Cloud khususnya diimplementasikan dan di-hosting pada penyedia tempat hostingan web untuk melayani sistem konsultasi dan bimbingan online berbasis web menggunakan webrtc studi kasus Fakultas Teknik Universitas Suryakancana.

\subsection{Usecase Diagram}

Usecase diagram memperlihatkan tiga aspek sistem yaitu actor, usecase dan lingkup sistem / sub sistem. Memperlihatkan hubungan antara aktor dan fungsi yang dapat dilakukan oleh aktor dalam ruang lingkup sistem. Usecase diagram yang akan dibangun terdapat pada gambar 3.

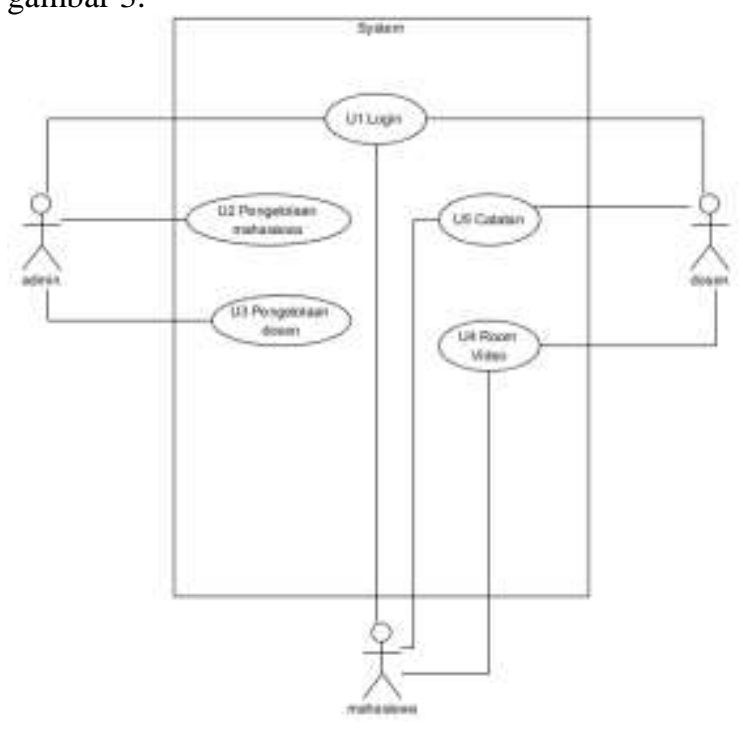

Gambar 5 Usecase Diagram 


\subsection{Class Diagram}

Class diagram merupakan salah satu diagram utama dari UML untuk menggambarkan class atau blueprint objcet pada sebuah sistem. Analisis pembentukan class diagram merupakan aktivitas inti yang sangat mempengaruhi arsitektur piranti lunak yang dirancang hingga ke tahap pengkodean. Berikut ini merupakan class diagram dari pembuatan sistem konsultasi dan bimbingan online berbasis web.

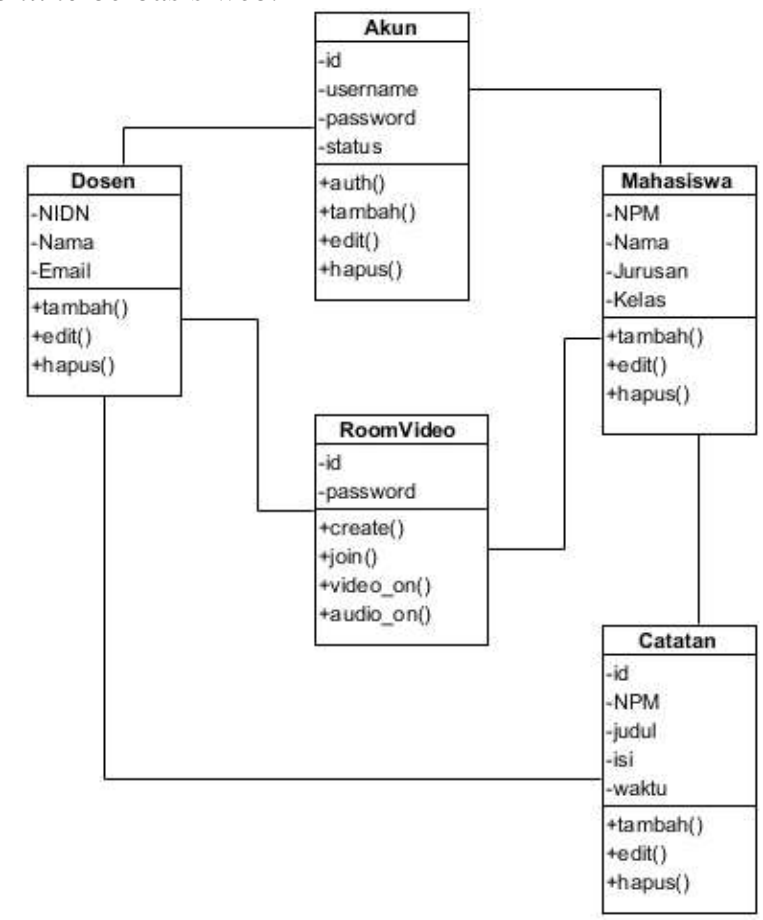

Gambar 6 Class Diagram

\section{Perancangan Sistem}

Desain / perancangan dilakukan sebelum aplikasi dibuat. Perancangan berarti kita berdiri di dua dunia, yaitu dunia teknologi dan dunia manusia serta tujuannya, dan mencoba menyatukan bersama. Pemodelan perancangan bertujuan untuk merincikan arsitektur perangkat lunak, struktur data, antar muka dan komponen lain yang bertujuan untuk mengimplementasikan sistem.

Produk yang dihasilkan terdiri dari arsitektur, antar muka, level komponen, dan deployment.(Roger S. Pressman 2012) Berikut ini adalah halaman sistem konsultasi dan bimbingan online. a. Antarmuka Halaman Login

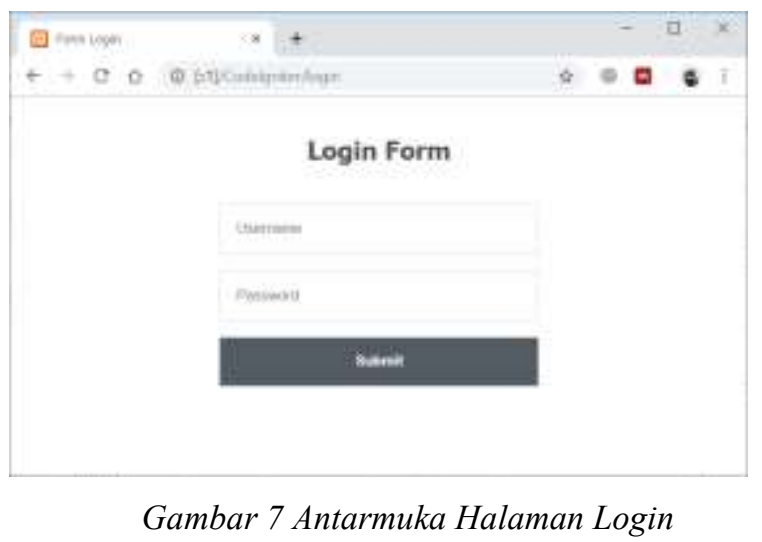

b. Antarmuka Halaman Pengelolaan Akun

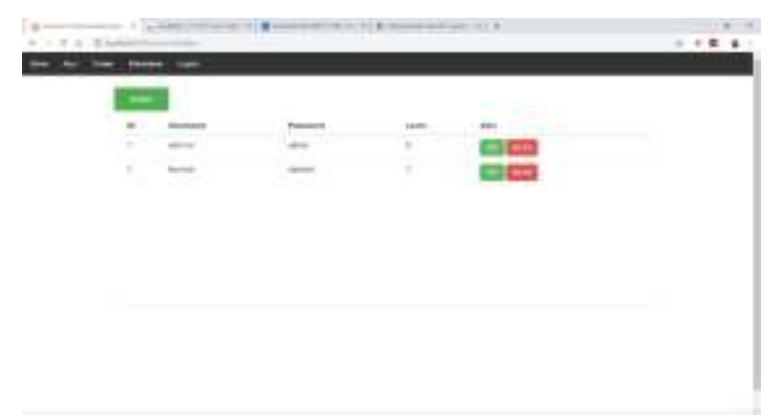

Gambar 8 Antarmuka Halaman Pengelolaan Akun

c. Antarmuka Halaman Pengelolaan Mahasiswa

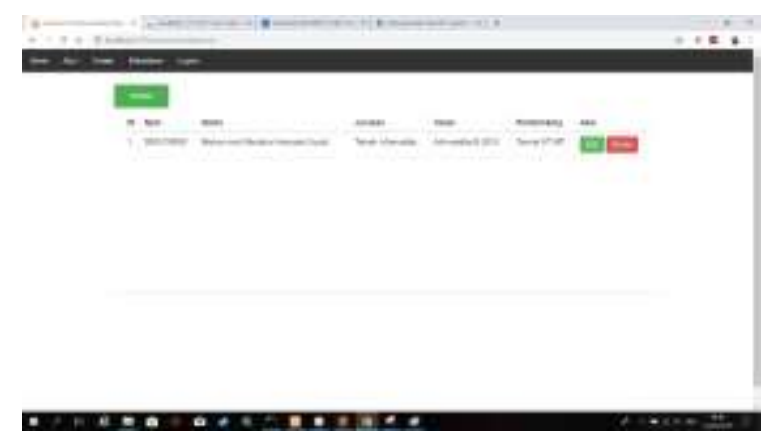

Gambar 9 Antarmuka Halaman Pengelolaan Mahasiswa 


\section{d. Antarmuka Halaman Pengelolaan Dosen}
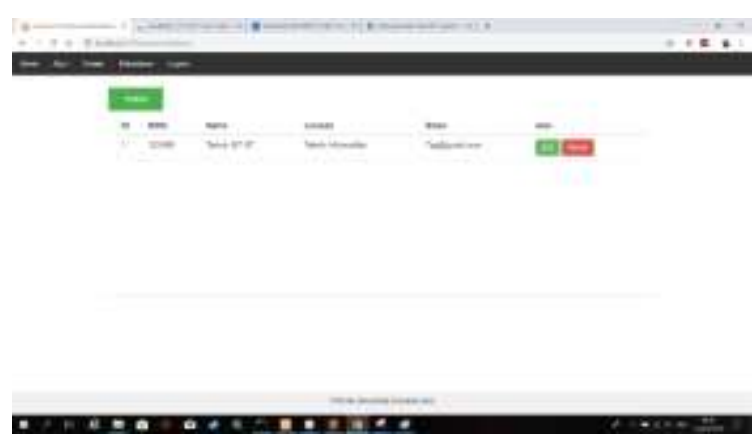

Gambar 10 Antarmuka Halaman Pengelolaan Dosen

e. Antarmuka Halaman Video Room

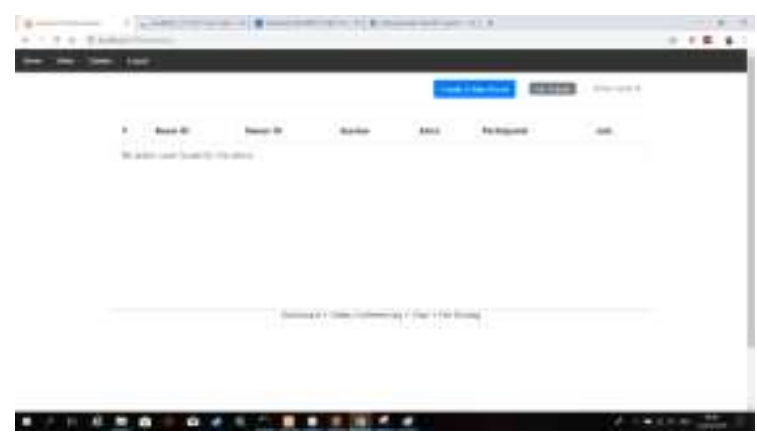

Gambar 11 Antarmuka Halaman Video Room

\section{f. Antarmuka Halaman Video Stream}

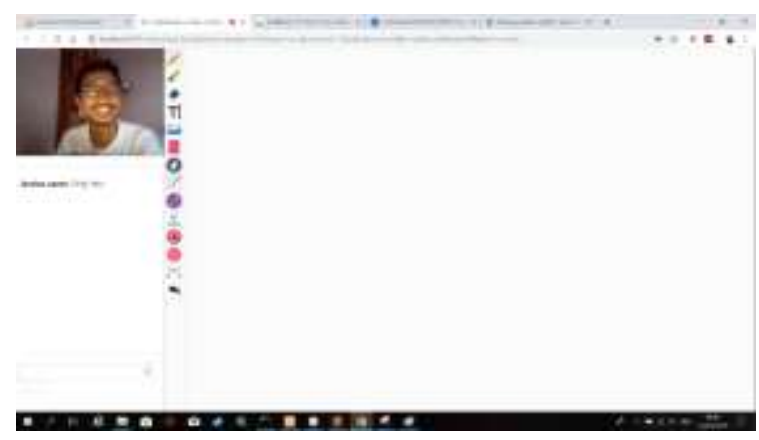

Gambar 12 Antarmuka Halaman Video Stream

g. Antarmuka Halaman Catatan

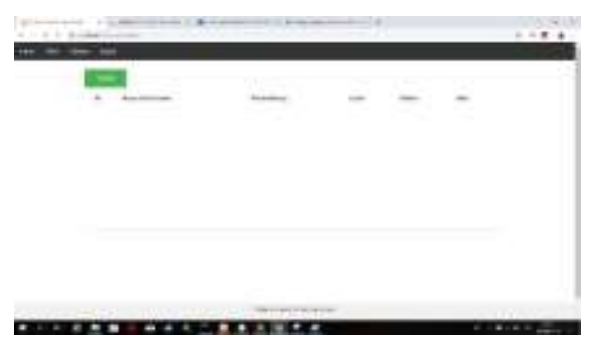

Gambar 13 Antarmuka Halaman Catatan

\section{Pengujian Sistem}

Pengujian merupakan bagian yang penting dalam siklus pengembangan perangkat lunak. Pengujian dilakukan untuk menjamin kualitas dan juga mengetahui kelemahan dari perangkat lunak. Tujuan dari pengujian ini adalah untuk menjamin bahwa perangkat lunak yang dibangun memiliki kualitas yang handal. Pengujian perangkat lunak ini menggunakan metode pengujian black box.

\section{Kesimpulan}

Berdasarkan hasil analisis selama melakukan penelitian ini, dalam pembuatan Sistem konsultasi dan bimbingan online berbasis web menggunakan webrtc, maka kesimpulannya yang dapat diambil sebagai berikut: 1. Berhasil dibuatnya sistem konsultasi dan bimbingan online berbasis web menggunakan webrtc di fakultas teknik dengan menggunakan UML (Unified Modeling Langguage) sebagai bahasa pemodelannya, dan bahasa pemograman PHP untuk mentransformasikan dari bentuk model kedalam bentuk sebuah code program aplikasi.

2. Dengan adanya sistem ini, Seorang admin dapat melakukan pengelolaan data dosen, pengelolaan data mahasiswa dan akun, dan sedangkan seorang user dapat melakukan bimbingan online dengan dosen pembimbing.

3. Mempermudah pihak mahasiswa untuk bimbingan dan konsultasi dengan dosen di lingkungan kampus maupun di luar lingkungan kampus.

\section{Saran}

Saran yang dapat diambil dari hasil kesimpulan yang telah dipaparkan diatas, maka dalam hal ini sebuah sistem digunakan untuk melakukan bimbingan online dan mengelola data data mahasiswa dan dosen, yang diharapkan dapat bermanfaat bagi instansi dan penggunanya. Untuk kedepannya sistem ini dapat dikembangkan kembali dalam hal penggunaan sistem di aplikasi mobile, yang lebih bermanfaat bagi penggunanya, mau mahasiswa, dosen, dan lingkungan organisasi mahasiswa.

\section{Daftar Pustaka}

[1.] Abdulloh, Rohi. 2015. Web Programing Is Easy. Jakarta: PT Elex Media Komputindo.

[2.] Dedy Bagus Rusdianto, Titik Lusiani, Teguh sutanto. n.d. "RANCANG BANGUN APLIKASI KONSULTASI MAKANAN SEHAT BAGI PENDERITA DIABETES BERBASIS MOBILE MENGGUNAKAN TEKNOLOGI J2ME."

[3.] Eriyanto. 2012. "Ilmu Sistem: Meningkatkan Mutu Dan Efektifitas Manajemen."

[4.] Lukmanul Hakim, Uus Musalini. 2004. Cara Cerdas Menguasai Layout,Desain Dan. Aplikasi Web. jakarta: PT Elex Media Komputindo.

[5.] Ministry of Education and Culture. 2014. "Peraturan Menteri Pendidikan Dan 
Kebudayaan Republik Indonesia Tentang Bimbingan Dan Konseling Pada Pendidikan Dasar Dan Pendidikan Menengah.” 1-7.

[6.] Pr, Equar. 2012. “Aplikasi Web Node.Js.” Pp. 130 in.

[7.] Roger S. Pressman, PH. D. 2012. Rekayasa Perangkat Lunak. 7th ed. edited by D. Hardjono. Yogyakarta: ANDI.

[8.] Sisca rizki aprilia, Rini Rachmawati. 2013. "Penyediaan Dan Pemanfaatan Layanan Konsultasi Belajar Siswa Secara Online Dalam Sistem Pembelajaran Siswa Di Kota Yogyakarta." 84:487-92.

[9.] Sitepu, Herry, Faris Mazini Muchma, and Dina Angela. 2006. "Pengembangan Aplikasi ELearning Berbasis WebRTC.” 11(2):71-80. 